\title{
Erythropoietin attenuates hyperoxia-induced lung injury by upregulating epidermal growth factor-like domain 7 in newborn rats
}

\author{
HUANJIN CUI, JIAYU HE, HONGWU CHEN, JINWEN CHEN, XINHUA QIAN and WEIMIN HUANG
}

Department of Neonatology, Nanfang Hospital, Southern Medical University, Guangzhou, Guangdong 510515, P.R. China

Received July 14, 2016; Accepted November 3, 2016

DOI: $10.3892 /$ br. 2016.820

\begin{abstract}
The aim of the present study was to observe the effects of recombinant human erythropoietin (rhEPO) on the expression of epidermal growth factor-like domain 7 (EGFL7) and cell apoptosis in lung tissue following hyperoxic lung injury in newborn rats. The 96 Sprague-Dawley newborn rats were randomly divided into 4 groups $(n=24)$ as follows: Room air-exposed control group, room air-exposed rhEPO-treated group, hyperoxia-exposed group and the hyperoxia-exposed rhEPO-treated group. Pups $(n=8)$ from each group were sacrificed on postnatal days 3,7 and 14. The pulmonary morphometric and microvessel density changes were observed. In addition, the mRNA and protein expression levels of EGFL7, B-cell lymphoma 2 (Bcl-2) and Bcl-2-like protein 4 (Bax) in lung tissue samples were measured. The rats in the hyperoxia-exposed group exhibited alveolar and pulmonary vascular dysplasia, as well as low mRNA and protein expression levels of EGFL7 and Bcl-2, in addition to high level of Bax in the lung tissue samples when compared with the room air-exposed control group $(\mathrm{P}<0.05)$. However, in the hyperoxia-exposed rhEPO-treated group the lung histopathology was improved, and the protein and mRNA expression levels of EGFL7 and Bcl-2 were increased compared with the hyperoxia-exposed group $(\mathrm{P}<0.05)$. Furthermore, the expression level of Bax was lower than that of the hyperoxia-exposed group $(\mathrm{P}<0.05)$. The present study demonstrated that rhEPO promotes alveolar development and increases pulmonary vascular density by upregulating the expression level of EGFL7 in hyperoxia-induced lung injury of newborn rats.
\end{abstract}

Correspondence to: Professor Weimin Huang, Department of Neonatology, Nanfang Hospital, Southern Medical University, Guangzhou, Guangdong 510515, P.R. China

E-mail: hwnnet@21cn.com

Key words: erythropoietin, hyperoxia, bronchopulmonary dysplasia, epidermal growth factor-like domain 7, pulmonary vascular

\section{Introduction}

Bronchopulmonary dysplasia (BPD) is one of the most common complications observed in premature infants, approximately $12-32 \%$ newborn infants with a gestational age of $<32$ weeks develop BPD $(1,2)$. BPD was first reported and defined as a pulmonary disease following mechanical ventilation of infants with respiratory distress syndrome, characterized by airway injury, inflammation and lung fibrosis by Northway et al $(3,4)$. Hyperoxia contributes to the development of BPD in human preterm infants and a similar lung phenotype characterized by alveolar and pulmonary vascular simplification in newborn rats $(5)$.

Certain studies have demonstrated that development of the pulmonary vasculature is a necessary factor for proper alveolarization. Furthermore, pulmonary vasculogenesis and angiogenesis are necessary for alveolarization during normal lung development. Injury to the developing pulmonary circulation during a critical period of lung growth may lead to lung hypoplasia (6-8).

Epidermal growth factor-like domain 7 (EGFL7) is a protein secreted from endothelial cells and is role in vascular tubulogenesis. It has been found that EGFL7 gene expression levels decrease significantly after hyperoxic exposure in neonatal rat lungs. Furthermore, EGFL7 may protect endothelial cells from hyperoxia-induced apoptosis by inhibition of the mitochondria-dependent apoptosis pathway $(9,10)$.

Erythropoietin (EPO) is a $30.4-\mathrm{kDa}$ glycoprotein that regulates the rate of red blood cell production, through binding to its specific cell surface receptors (11). It was once considered to be a regulator of erythropoiesis by controlling the apoptosis, proliferation and differentiation of erythroid precursor cells over an extended period of time (12). Animal experiments have revealed that EPO exerts protective effects against hyperoxic lung injury; these findings indicate that treatment of premature infants with EPO might reduce the risk of developing BPD. However, the mechanisms remain unknown, an improved understanding of the mechanism of action of EPO is required to translate this experimental result into clinical trials in BPD patients $(13,14)$.

The aim of the current study was to demonstrate whether recombinant human (rh)EPO treatment could attenuate hyperoxia-induced lung damage, and if so, whether this protective effect is mediated by up-modulating the expression of EGFL7 in newborn rats. 


\section{Materials and methods}

Animal experiments. The current study was approved by the Ethics and Research Committee of Southern Medical University (Guangzhou, China). All research was conducted according to the Guide for the Care and Use of Laboratory Animals of the National Institutes of Health. Ten pregnant Sprague-Dawley rats (on gestation day 20) were provided by the Experimental Animal Center of Southern Medical University. A total of 109 pups were delivered spontaneously on the following day. Among them 96 pups were selected and, within $12 \mathrm{~h}$ of their birth, were randomly divided into four groups $(n=24)$ as follows: Room air-exposed control group, room air-exposed rhEPO-treated group, hyperoxia-exposed group, and the hyperoxia-exposed rhEPO-treated group. The two hyperoxia-exposed groups were placed in an oxygen chamber and exposed to oxygen $\left(\mathrm{FiO}_{2}=0.85 \pm 0.02\right)$ continuously, the room air-exposed rhEPO-treated and hyperoxia-exposed rhEPO-treated groups received 1,200 IU/kg rhEPO subcutaneously $30 \mathrm{~min}$ before oxygen exposure and 2 days after birth. Isodose saline was administered to the pups in the room air-exposed control and hyperoxia-exposed pups according to the same protocol. The chambers were opened for $1 \mathrm{~h}$ daily to provide water and food, to change bedding and to exchange nursing dams between the hyperoxic and room air chambers to protect the nursing dams from oxygen toxicity. On days 3, 7 and 14, eight rats from each group were anesthetized with $60 \mathrm{mg} / \mathrm{kg}$ pentobarbital (intraperitoneal injection; Nanjing KeyGen Biotech Co., Ltd., Nanjing, China). Lungs were exposed by thoracotomy and, after exsanguination by transecting the aorta and inferior vena cava, the right ventricle was punctured and lungs were perfused with $3 \mathrm{ml}$ phosphate-buffered saline (PBS) at $25 \mathrm{cmH}_{2} \mathrm{O}$. These lung tissue samples were collected for the subsequent experiments.

Assessment of lung histological changes. Following deep anesthesia with $60 \mathrm{mg} / \mathrm{kg}$ pentobarbital via intraperitoneal injection, the rat chests were opened, and the left lungs were excised and fixed overnight in $4 \%$ paraformaldehyde at $4^{\circ} \mathrm{C}$. The tissue samples were dehydrated, transparentized and embedded with ethanol, xylene and paraffin, respectively. Sections $(4 \mu \mathrm{m})$ were cut from the paraffin blocks and stained with hematoxylin and eosin to observe the histological changes. A quantitative analysis of the radial alveolar count (RAC) and the mean septal wall thickness was performed as previously described $(5,15)$. These were used to evaluate the effect of hyperoxia on lung histological damage and the effect of rhEPO in modulating hyperoxia-induced lung injury.

Immunohistochemistry. For CD31 immunohistochemistry, the lung tissue samples were embedded in paraffin after fixation in $4 \%$ paraformaldehyde, and sliced into $4-\mu \mathrm{m}$-thick sections. The sections were dewaxed and hydrated in xylene and a series of graded ethanol, and the sections were antigen retrieved in citrate buffer ( $\mathrm{pH}$ 6.0) using a microwave for $15 \mathrm{~min}$, and incubated in $3 \% \mathrm{H}_{2} \mathrm{O}_{2}$ for 20 min to eliminate endogenous peroxidase activity. The slides were incubated with a primary mouse CD31 monoclonal antibody (cat. no. ab64543; dilution, 1:200; Abcam, Cambridge, MA, USA) at $4^{\circ} \mathrm{C}$ overnight. The sections were then washed three times with $1 \mathrm{X}$ PBS (pH 7.2-7.4) and incubated with a biotinylated peroxidase-conjugated goat anti-mouse secondary antibody (cat. no. 115225205; dilution, 1:1,000; Jackson ImmunoResearch Laboratories, West Grove, PA, USA) at $37^{\circ} \mathrm{C}$ for $30 \mathrm{~min}$ and $0.1 \% 3,3^{\prime}$-diaminobenzidine substrate, using the standard streptavidin-biotin-based method (10). The sections were counterstained with hematoxylin. The negative control was incubated with $1 \mathrm{X}$ PBS (pH 7.2-7.4) instead of the primary antibody at $37^{\circ} \mathrm{C}$ for $30 \mathrm{~min}$. The slides were observed under a light microscope (Eclipse TE200; Nikon Corporation, Tokyo, Japan) at a magnification of $x 400$. The cytoplasmic brown granule indicated positive expression of $\mathrm{CD} 31$ and the average integrated optical density (AIOD) values of CD31 were measured. The vascular density was quantified by AIOD of CD31 through measuring the positive area of CD31 immunostaining relative to the total area of lung parenchymal cells using Image-Pro Plus 6.0 (Media Cybernetics, Rockville, MD, USA) of differential interference contrast images, as previously described by Wang and Huang (10).

\section{Reverse transcription-quantitative polymerase chain reaction} $(R T-q P C R)$. Total RNA from lung tissue samples was extracted using RNAiso Plus (Takara Bio, Inc., Otsu, Japan) according to the manufacturer's instructions. RT-PCR was performed with the PrimeScript RT-PCR kit (Takara Bio, Inc.). The PCR primers for EGFL7, Bax, Bcl-2 and $\beta$-actin were designed and synthesized by Invitrogen (Thermo Fisher Scientific, Inc., Waltham, MA, USA). The sequences of the primers used were asfollows (10): Forward, 5'-CCGAACCATCTACCGGACTG-3' and reverse, 5'-GCCTGTCTGTCACCCATTCA-3' for EGFL7; forward, 5'-AGAGGATGGCTGGGGAGAC-3' and reverse, 5'-CGCTCAGCTTCTTGGTGGAT-3' for Bax; forward, 5'-ACCCCTGGCATCTTCTCCT-3' and reverse, 5'-CGACG GTAGCGACGAGAG-3' for Bcl-2; and forward, 5'-AGGGAA ATCGTGCGTGACAT-3' and reverse, 5'-GAACCGCTC ATTGCCGATAG-3' for $\beta$-actin. The amplification reaction was conducted using an Applied Biosystems 7500 Real-Time PCR System under the following cycling conditions: $95^{\circ} \mathrm{C}$ for $30 \mathrm{sec}$, then $95^{\circ} \mathrm{C}$ for $5 \mathrm{sec}$, and $60^{\circ} \mathrm{C}$ for $34 \mathrm{sec}$ for 40 cycles. The expression level of $\beta$-actin served as the internal control and the relative quantification of mRNA expression was calculated using the $2^{-\Delta \Delta \mathrm{Ct}}$ method (16).

Western blot analysis. Total proteins were collected from the lung tissue samples of the pups, using lysis buffer and the Total Protein Extraction Reagent kit (Nanjing KeyGen Biotech Co., Ltd.), and the protein concentration was determined using a BCA protein assay kit (Nanjing KeyGen Biotech Co., Ltd.). Equal loading protein ( $30 \mu \mathrm{g} / \mathrm{lane})$ were dissolved in $12 \%$ SDS-PAGE gel (Guangzhou TianJun Biotech Co., Ltd., Guangzhou, China) for protein separation and transferred to polyvinylidene fluoride membranes for $60 \mathrm{~min}$ at $200 \mathrm{~mA}$. The membranes were blocked with 5\% skimmed milk in Tris-buffered saline and 0.1\% Tween-20 (Guangzhou TianJun Biotech Co., Ltd.) for $1 \mathrm{~h}$ at room temperature. The membranes were subsequently incubated with primary rabbit polyclonal antibodies against EGFL7 (cat. no. 19291-1-AP; dilution, 1:500; ProteinTech Group, Inc., Chicago, IL, USA), Bax (cat. no. ab182733; dilution, 1:1,000; Epitomics; Abcam, Cambridge, USA), Bcl-2 (cat. no. BS1511; dilution, 1:500; Bioworld Technology, Inc., St. Louis Park, MN, USA) and $\beta$-actin (cat. no. BS1002; dilution, 1:2,000; Bioworld Technology, Inc.) overnight at $4^{\circ} \mathrm{C}$. 
Table I. RAC and mean ST in each group.

\begin{tabular}{|c|c|c|c|c|}
\hline \multirow[b]{2}{*}{ Group } & \multicolumn{2}{|c|}{ RAC } & \multicolumn{2}{|c|}{$\mathrm{ST}(\mu \mathrm{m})$} \\
\hline & Day 7 & Day 14 & Day 7 & Day 14 \\
\hline Control & $6.05 \pm 0.22$ & $8.43 \pm 0.44$ & $7.02 \pm 0.22$ & $6.25 \pm 0.59$ \\
\hline Control + EPO & $6.23 \pm 0.14$ & $8.42 \pm 0.27$ & $6.78 \pm 0.43$ & $6.04 \pm 0.52$ \\
\hline Hyperoxia & $5.23 \pm 0.12^{\mathrm{a}}$ & $5.52 \pm 0.18^{\mathrm{a}}$ & $9.73 \pm 0.35^{\mathrm{a}}$ & $10.74 \pm 0.32^{\mathrm{a}}$ \\
\hline Hyperoxia + EPO & $5.84 \pm 0.17^{\mathrm{b}, \mathrm{c}}$ & $7.55 \pm 0.43^{\mathrm{b}, \mathrm{c}}$ & $7.65 \pm 0.33^{\mathrm{b}, \mathrm{c}}$ & $6.47 \pm 0.25^{\mathrm{c}}$ \\
\hline
\end{tabular}

Values are presented as means \pm standard deviation. ${ }^{\mathrm{a}} \mathrm{P}<0.01$ and ${ }^{\mathrm{b}} \mathrm{P}<0.05$ vs. the control group; ${ }^{\mathrm{c}} \mathrm{P}<0.01$ vs. the hyperoxia group. $\mathrm{RAC}$, radial alveolar count; ST, septal wall thickness; EPO, erythropoietin.

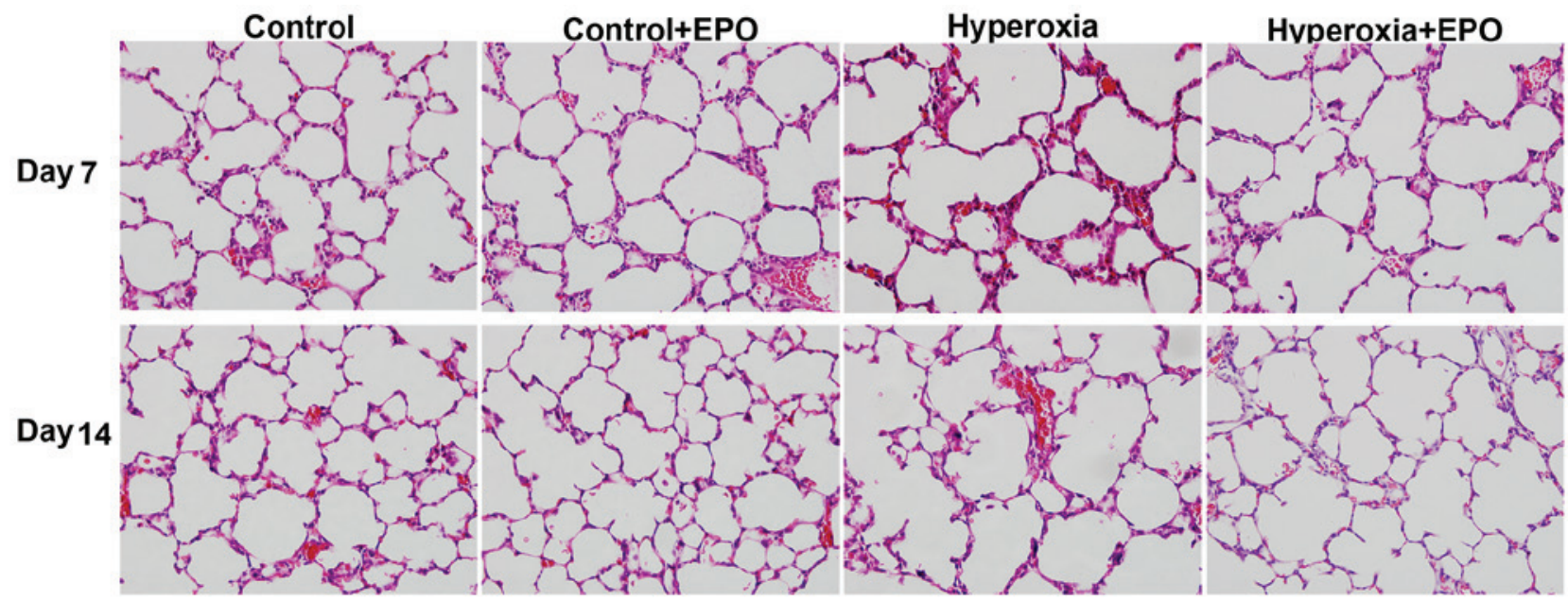

Figure 1. Hematoxylin and eosin staining of lung tissue (magnification, x400). In the control group and control + EPO group, the lung was well-developed. Inflammatory cells infiltrating the interstitial lung and marked alveolar simplification were observed in the hyperoxia group, and the septal walls were noticeably thicker in the lung on days 7 and 14. EPO, erythropoietin.

The next day, the membranes were incubated with anti-rabbit (H+L) HRP secondary antibody (cat. no. AP0032M; dilution, 1:3,000; Bioworld Technology, Inc.) at room temperature for $60 \mathrm{~min}$. The protein bands were visualized with an enhanced chemiluminescence reaction kit (EMD Millipore, Billerica, MA, USA) on a Chemi Imager 5500 image analysis instrument (Alpha Innotech Corp., San Leandro, CA, USA). Subsequently, the density values of the bands were analyzed using Quantity One (version 4.6.2 PC) software (Bio-Rad Laboratories, Inc., Hercules, CA, USA). Relative protein expression levels of EGFL7, Bax and Bcl-2 were normalized to $\beta$-actin.

Statistical analysis. All data are provided as means \pm standard deviation. Comparison among the groups was performed by one-way analysis of variance and Student's t-test. $\mathrm{P}<0.05$ was considered to indicate a statistically significant difference.

\section{Results}

Lung histology and morphometric analyses. Lung histology images obtained at a magnification of x400 are presented in Fig. 1. In the room air-exposed control group and room air-exposed rhEPO-treated group, no histological damage or inflammatory infiltrates, or septal wall thickening were observed. Furthermore, the terminal alveoli were well formed. By contrast, in the hyperoxia-exposed group rats, a large number of inflammatory cells infiltrating the interstitial lung was observed, as well as marked alveolar simplification and the septal walls were noticeably thicker. Treatment with rhEPO attenuated septal wall thickening and markedly increased the RAC. In addition, the morphological characteristics were similar to the room air-exposed control group. Compared with the hyperoxia-exposed group, the RAC was significantly increased and the septal wall thickness was significantly decreased in the hyperoxia-exposed rhEPO-treated group $(\mathrm{P}<0.05$; Fig. 1 and Table I).

Immunohistochemical analysis of CD31 expression levels and vascular density. Cytoplasmic brown granules indicated the positive expression of CD31. Vascular density was quantified by measuring the positive area of CD31 immunostaining relative to the total area of the lung parenchymal cells. CD31and vascular density in the hyperoxia-exposed group were decreased compared with the control group at each time-point. The CD31 and vascular density in the hyperoxia-exposed rhEPO-treated group were markedly increased when compared with the hyperoxia-exposed group on postnatal days 7 and 14 $(\mathrm{P}<0.05$; Fig. 2 and Table II). 
Table II. Relative protein levels of CD31 and vascular density of rat lung tissue samples treated with or without EPO.

\begin{tabular}{|c|c|c|c|c|}
\hline \multirow[b]{2}{*}{ Group } & \multicolumn{2}{|c|}{ AIOD of CD31 } & \multicolumn{2}{|c|}{ Vascular density ( $\%$ area) } \\
\hline & Day 7 & Day 14 & Day 7 & Day 14 \\
\hline Control & $42.60 \pm 3.22$ & $123.73 \pm 10.12$ & $6.02 \pm 0.25$ & $10.88 \pm 0.53$ \\
\hline Control + EPO & $43.33 \pm 3.61$ & $125.98 \pm 4.79$ & $6.17 \pm 0.21$ & $11.00 \pm 0.63$ \\
\hline Hyperoxia & $18.10 \pm 0.39^{\mathrm{a}}$ & $49.20 \pm 5.44^{\mathrm{a}}$ & $3.78 \pm 0.18^{a}$ & $6.43 \pm 0.44^{\mathrm{a}}$ \\
\hline Hyperoxia + EPO & $40.10 \pm 2.43^{b}$ & $115.40 \pm 8.34^{\mathrm{b}}$ & $5.57 \pm 0.46^{\mathrm{b}}$ & $9.95 \pm 0.66^{b}$ \\
\hline
\end{tabular}

Values are presented as means \pm standard deviation. ${ }^{a} \mathrm{P}<0.01$ vs. the control group; ${ }^{\text {b }}<0.01$ vs. the hyperoxia group. $\mathrm{CD}$, cluster of differentiation; EPO, erythropoietin; AIOD, average integrated optical density.

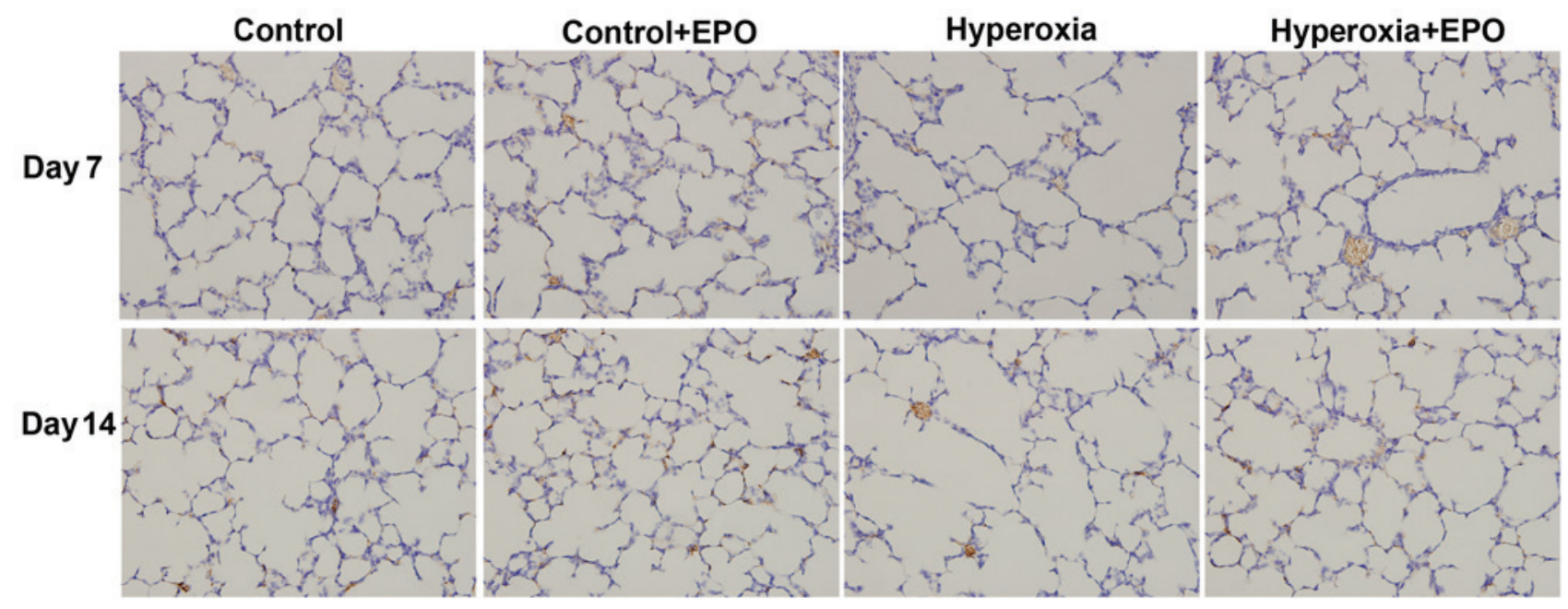

Figure 2. CD31 immunohistochemistry of lung tissue samples from each group. Tissue samples were immunostained with a monoclonal antibody to CD31 (magnification, x400). CD, cluster of differentiation; EPO, erythropoietin.

mRNA expression levels of EGFL7, Bax and Bcl-2 in lung tissue samples by RT-qPCR. The EGFL7 and Bcl-2 mRNA expression levels from the lung tissue samples of the hyperoxia-exposed group pups were lower, although the Bax mRNA expression level was higher when compared with the room air-exposed control group on postnatal days 3, 7 and $14(\mathrm{P}<0.01)$. In the hyperoxia-exposed rhEPO-treated group, the mRNA expression levels of EGFL7 and Bcl-2 were upregulated, while the Bax mRNA expression level was downregulated significantly when compared with the hyperoxia-exposed group at each time-point $(\mathrm{P}<0.05)$. No significant differences were identified among the room air-exposed control group, room air-exposed rhEPO-treated group and the hyperoxia-exposed rhEPO-treated group (Fig. 3).

Protein expression levels of EGFL7, Bax and Bcl-2 in lung tissue samples by western blotting. The protein expression levels of EGFL7, Bax, and Bcl-2 in lung tissue samples obtained from each group were examined by western blotting. The protein expression levels of EGFL7 and Bcl-2 in the hyperoxia-exposed group were decreased, while the protein expression level of Bax was elevated when compared with the room air-exposed control group on postnatal days 3,
7 and $14(\mathrm{P}<0.01)$. In the hyperoxia-exposed rhEPO-treated group, significantly higher expression levels of EGFL7 and Bcl-2 protein were identified, while the expression level of Bax protein was decreased when compared with the hyperoxia-exposed group ( $\mathrm{P}<0.05$; Fig. 4).

\section{Discussion}

BPD is the most common complication of prematurity, despite its high incidence on preterm newborns, its pathogenesis is not yet clearly understood and there are no effective therapeutic strategies. BPD is a multifactorial disease characterized by impaired alveolar and vascular development (17). Therapy with hyperoxia is often used to treat newborns with respiratory disorders; however, high concentrations and extended durations of oxygen exposure in a newborn may lead to oxidative stress injury and lung epithelial cell death in the immature lung, which is crucial in the development of BPD $(18,19)$. Previous studies have demonstrated that pulmonary vasculogenesis and angiogenesis are necessary for alveolarization during normal lung development. Alveolar development and pulmonary vascular development are interlocked processes, as evidenced by the finding that experimental inhibition of angiogenesis during fetal lung development results in the arrest of distal 
A
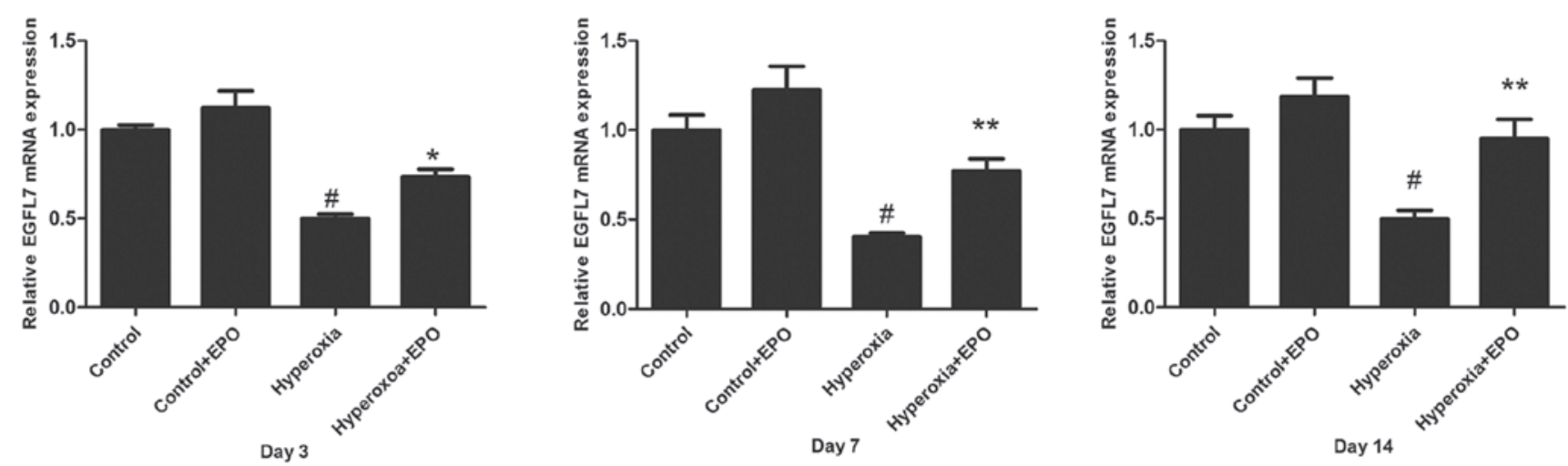

B
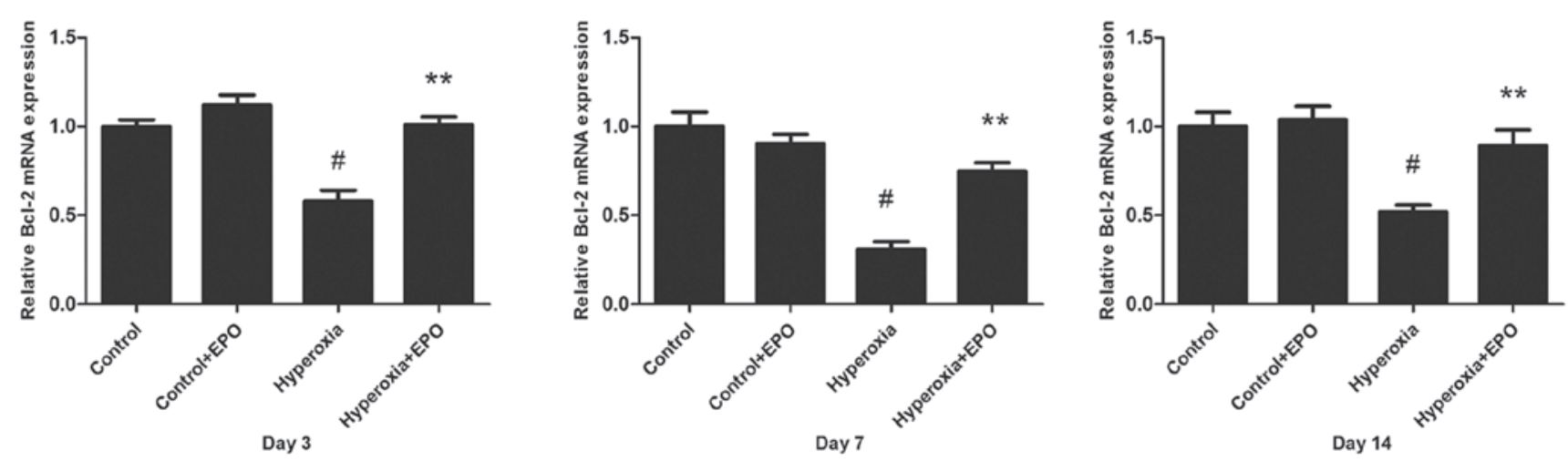

C
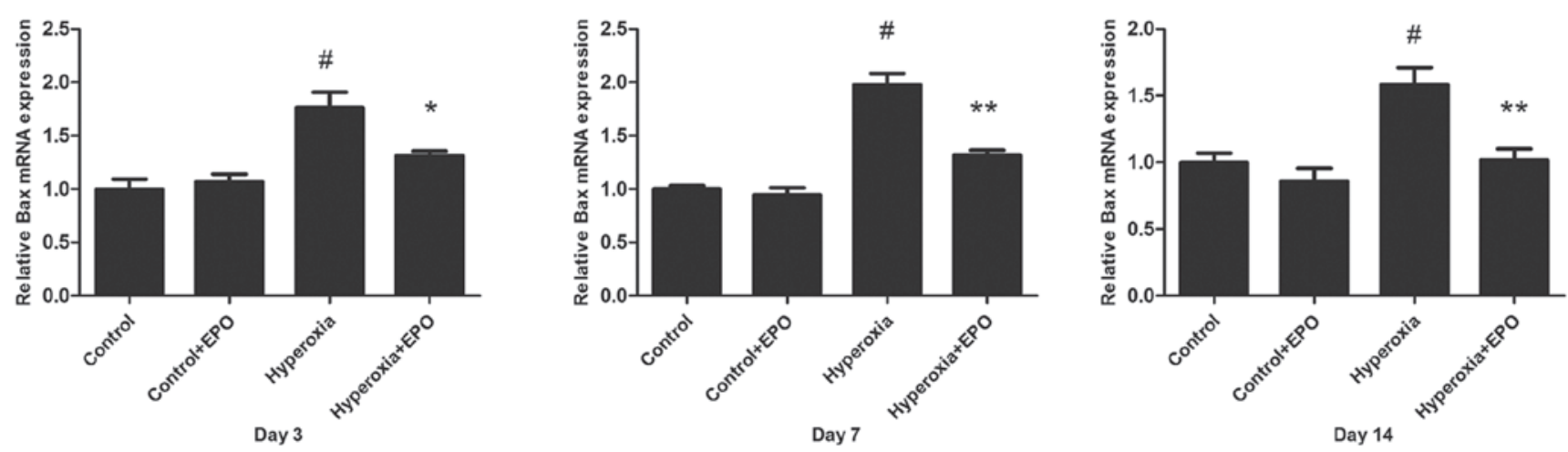

Figure 3. mRNA expression levels of (A) EGFL7, (B) Bcl-2 and (C) Bax were measured using the $2^{-\Delta \Delta C q}$ method. Values are presented as the means \pm standard deviation $(\mathrm{n}=8)$. $\mathrm{P}<0.05$ vs. time-matched hyperoxia group; ${ }^{* *} \mathrm{P}<0.01$ vs. time-matched hyperoxia group. ${ }^{*} \mathrm{P}<0.01$ vs. control group. EGFL7, epidermal growth factor-like domain 7; Bcl-2, B-cell lymphoma 2; Bax, bcl-2-like protein 4; BPD, bronchopulmonary dysplasia.

airspace development, and that the disruption of normal lung vascular growth is vital in the pathogenesis of BPD $(20,21)$.

EPO is a $30.4-\mathrm{kDa}$ glycoprotein that regulates the rate of red blood cell production, through binding to its specific cell surface receptors; EPO is an angiogenic factor, as well as an antioxidant due to decreasing the plasma iron concentration and increasing the ability of plasma to inhibit lipid peroxidation $(11,22)$. As abnormal vascular growth are proposed to be major contributing factors in the pathogenesis of BPD, the benefits of EPO treatment in this disease have previously been investigated (11). Studies have demonstrated that rhEPO treatment attenuated hyperoxia-induced lung injury by down-modulating the inflammatory responses and decreasing apoptosis in neonatal rats $(14,23)$.
CD31 is a $130-\mathrm{kDa}$ molecular weight protein and a member of the immunoglobulin gene superfamily (24). CD31 is expressed in newly formed, small blood vessels and pre-existing vessels, and CD31 is commonly used as an endothelial cell marker in vessels $(25,26)$. The vascular density is quantified by measuring the positive area of CD31 immunostaining relative to the total area of lung parenchymal cells. In the current study, the alveolar and capillary damage were identified to be milder in the hyperoxia-exposed rhEPO-treated group when compared with the hyperoxia-exposed group. In addition, the vascular density significantly increased in the hyperoxia-exposed rhEPO-treated group when compared with the hyperoxia-exposed group. In the present study, EPO treatment reversed the negative effect of hyperoxia that 
A

Day 3

Day 7

Day 14
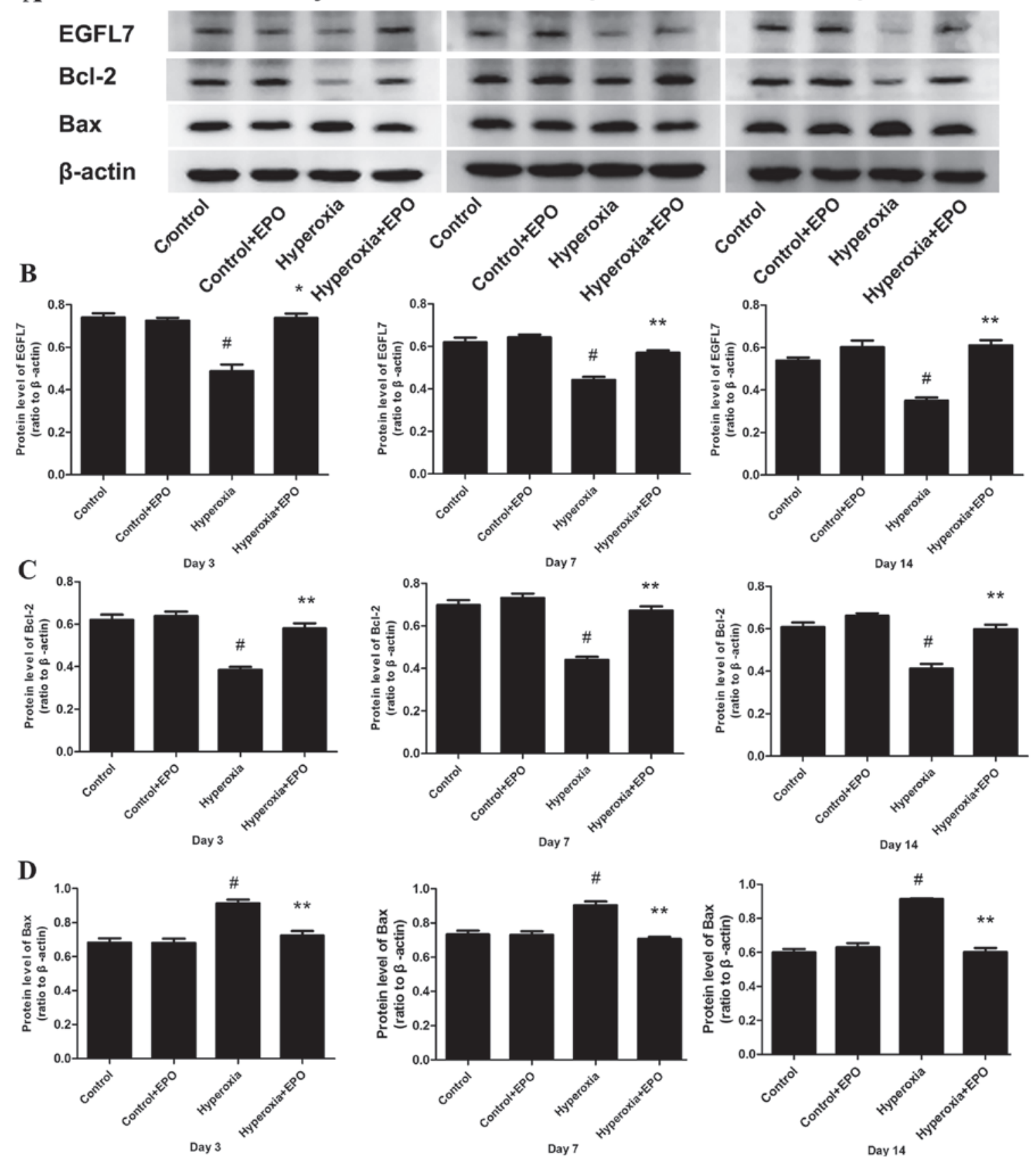

Figure 4. (A) Protein expression of EGFL7, Bcl-2 and Bax in lung tissue samples from each group was examined by western blot analysis. (B-D) Quantification of western blot analysis measured by the mean ratios of EGFL7/ $\beta$-actin, Bcl-2/ $\beta$-actin and Bax/ $\beta$-actin. $\beta$-actin served to verify equivalent loading. Values are the means \pm standard deviation $(n=8)$. ${ }^{*} \mathrm{P}<0.05$ and ${ }^{* *} \mathrm{P}<0.01$ vs. time-matched hyperoxia group; ${ }^{*} \mathrm{P}<0.01 \mathrm{vs}$. control group. EGFL7, epidermal growth factor-like domain 7; Bcl-2, B-cell lymphoma 2; Bax, bcl-2-like protein 4.

was observed in the hyperoxia-exposed group resulting in increased alveolar and pulmonary vascular injury.

In the present study, the hyperoxia-exposed group exhibited markedly decreased expression levels of EGFL7 mRNA and protein when compared with the control. However, the mRNA and protein expression levels of EGFL7 were significantly increased at each time-point in the hyperoxia-exposed rhEPO-treated group when compared with the hyperoxia-exposed group. EGFL7, also termed vascular endothelial statin, is an endothelial cell-derived secreted factor that is important in vascular tubulogenesis; diminished expression levels of EGFL7 may be associated with hyperoxia-induced endothelial cell death and lung injury, and hEGFL7 may protect endothelial cells from hyperoxia-induced apoptosis by inhibition of the mitochondria-dependent apoptosis pathway (9).

A previous study demonstrated that the overexpression of EGFL7 reduced the expression level of the pro-apoptotic protein, Bax, and increased the expression level of the anti-apoptotic protein, Bcl-2, which prevents hyperoxia-induced endothelial cell death and promotes lung vascular development (9). It is known that Bax promotes apoptosis through binding Bcl-2 and it inhibits the anti-apoptotic function during mitochondria-regulated programmed cell death (27). In the current study, the expression level of Bax was significantly 
increased in the hyperoxia-exposed group when compared with the air-exposed group, and it was decreased in the hyperoxia-exposed rhEPO-treated group when compared with the hyperoxia-exposed group; an opposite trend was observed in the expression level of Bcl-2. This suggests that rhEPO attenuates hyperoxia-induced lung injury and that this effect of rhEPO may occur through upregulating EGFL7 expression. Subsequently, the increased EGFL7 expression reduces the expression level of Bax and increases the expression level of Bcl-2, which prevents hyperoxia-induced endothelial cell death and promotes lung vascular development.

In conclusion, rhEPO treatment significantly attenuated hyperoxia-induced lung injury (such as decreased alveolization and increased cell apoptosis) by upregulating EGFL7 expression in newborn rats. These findings support the potential use of rhEPO as a therapeutic agent in the prevention of BPD. Further studies regarding dosage and safety are required for the translation of EPO treatment into clinical trials. Thus, rhEPO may have potential for use as a therapeutic strategy for BPD in neonates.

\section{Acknowledgements}

The present study was supported by the Guangdong Province Science and Technology Plan Project (grant no. 2013B051000049 awarded to Professor Weimin Huang).

\section{References}

1. Li C, Fu J, Liu H, Yang H, Yao L, You K and Xue X: Hyperoxia arrests pulmonary development in newborn rats via disruption of endothelial tight junctions and downregulation of $\mathrm{Cx} 40$. Mol Med Rep 10: 61-67, 2014.

2. Trembath A and Laughon MM: Predictors of bronchopulmonary dysplasia. Clin Perinatol 39: 585-601, 2012.

3. Lal CV and Ambalavanan N: Genetic predisposition to bronchopulmonary dysplasia. Semin Perinatol 39: 584-591, 2015.

4. Northway WH Jr, Rosan RC and Porter DY: Pulmonary disease following respirator therapy of hyaline-membrane disease. Bronchopulmonary dysplasia. N Engl J Med 276: 357-368, 1967.

5. Shivanna B, Zhang S, Patel A, Jiang W, Wang L, Welty SE and Moorthy B: Omeprazole attenuates pulmonary aryl hydrocarbon receptor activation and potentiates hyperoxia-induced developmental lung injury in newborn mice. Toxicol Sci 148: 276-287, 2015.

6. Jakkula M, Le Cras TD, Gebb S, Hirth KP, Tuder RM, Voelkel NF and Abman SH: Inhibition of angiogenesis decreases alveolarization in the developing rat lung. Am J Physiol Lung Cell Mol Physiol 279: L600-L607, 2000.

7. Remesal A, Pedraz C, San Feliciano L and Ludeña D: Pulmonary expression of vascular endothelial growth factor (VEGF) and alveolar septation in a newborn rat model exposed to acute hypoxia and recovered under conditions of air or hyperoxia. Histol Histopathol 24: 325-330, 2009.

8. Chang M, Bany-Mohammed F, Kenney MC and Beharry KD: Effects of a superoxide dismutase mimetic on biomarkers of lung angiogenesis and alveolarization during hyperoxia with intermittent hypoxia. Am J Transl Res 5: 594-607, 2013.
9. Xu D, Perez RE, Ekekezie II, Navarro A and Truog WE: Epidermal growth factor-like domain 7 protects endothelial cells from hyperoxia-induced cell death. Am J Physiol Lung Cell Mol Physiol 294: L17-L23, 2008.

10. Wang XH and Huang WM: Astragalus polysaccharides exert protective effects in newborn rats with bronchopulmonary dysplasia by upregulating the expression of EGFL7 in lung tissue. Int J Mol Med 34: 1529-1536, 2014.

11. Ozer EA, Kumral A, Ozer E, Yilmaz O, Duman N, Ozkal S, Koroglu T and Ozkan H: Effects of erythropoietin on hyperoxic lung injury in neonatal rats. Pediatr Res 58: 38-41, 2005.

12. Luo W, Hu L and Wang F: The protective effect of erythropoietin on the retina. Ophthalmic Res 53: 74-81, 2015.

13. Wang XL, Fu JH and Xue XD: Effects of hyperoxia on erythropoietin receptor expression in lung development of neonatal rats. Zhonghua Er Ke Za Zhi 49: 361-366, 2011 (In Chinese).

14. Lee JH, Sung DK, Koo SH, Shin BK, Hong YS, Son CS, Lee JW, Chang YS and Park WS: Erythropoietin attenuates hyperoxia-induced lung injury by down-modulating inflammation in neonatal rats. J Korean Med Sci 22: 1042-1047, 2007.

15. Martin CR, Zaman MM, Gilkey C, Salguero MV, Hasturk H, Kantarci A, Van Dyke TE and Freedman SD: Resolvin D1 and lipoxin A4 improve alveolarization and normalize septal wall thickness in a neonatal murine model of hyperoxia-induced lung injury. PLoS One 9: e98773, 2014.

16. Livak KJ and Schmittgen TD: Analysis of relative gene expression data using real-time quantitative PCR and the 2(-Delta Delta C(T)) Method. Methods 25: 402-408, 2001.

17. Carrera P, Di Resta C, Volonteri C, Castiglioni E, Bonfiglio S, Lazarevic D, Cittaro D, Stupka E, Ferrari M and Somaschini M; BPD and Genetics Study Group: Exome sequencing and pathway analysis for identification of genetic variability relevant for bronchopulmonary dysplasia (BPD) in preterm newborns: A pilot study. Clin Chim Acta 451 (Pt A): 39-45, 2015.

18. Spiteller G: The important role of lipid peroxidation processes in aging and age dependent diseases. Mol Biotechnol 37: 5-12, 2007.

19. Dang H, Wang S, Yang L, Fang F and Xu F: Upregulation of Shh and Ptcl in hyperoxia induced acute lung injury in neonatal rats. Mol Med Rep 6: 297-302, 2012.

20. D'Angio CT and Maniscalco WM: The role of vascular growth factors in hyperoxia-induced injury to the developing lung. Front Biosci 7: d1609-d1623, 2002.

21. Asikainen TM, Ahmad A, Schneider BK, Ho WB, Arend M, Brenner M, Günzler V and White CW: Stimulation of HIF-1alpha, HIF-2alpha, and VEGF by prolyl 4-hydroxylase inhibition in human lung endothelial and epithelial cells. Free Radic Biol Med 38: 1002-1013, 2005.

22. Bany-Mohammed FM, Slivka S and Hallman M: Recombinant human erythropoietin: Possible role as an antioxidant in premature rabbits. Pediatr Res 40: 381-387, 1996.

23. Ding L, Wu BQ, Huang JJ, Liu ZP and Chen L: Effect of erythropoietin on apoptosis following hyperoxic lung injury in neonatal rats. Zhongguo Dang Dai Er Ke Za Zhi 12: 576-579, 2010 (In Chinese).

24. Piedboeuf B, Gamache M, Frenette J, Horowitz S, Baldwin HS and Petrov P: Increased endothelial cell expression of platelet-endothelial cell adhesion molecule-1 during hyperoxic lung injury. Am J Respir Cell Mol Biol 19: 543-553, 1998.

25. Privratsky JR and Newman PJ: PECAM-1: Regulator of endothelial junctional integrity. Cell Tissue Res 355: 607-619, 2014.

26. Matsuda Y, Hagio M and Ishiwata T: Nestin: A novel angiogenesis marker and possible target for tumor angiogenesis. World J Gastroenterol 19: 42-48, 2013.

27. Oltvai ZN, Milliman CL and Korsmeyer SJ: Bcl-2 heterodimerizes in vivo with a conserved homolog, Bax, that accelerates programmed cell death. Cell 74: 609-619, 1993. 